\title{
COMPRAS INSTITUCIONAIS DE PRODUTOS DE AGRICULTORES FAMILIARES PARA ALIMENTAÇÃO ESCOLAR NO ESTADO DE SÃO PAULO SOB A VIGÊNCIA DA LEI FEDERAL 11.947/2009 ${ }^{1}$
}

\author{
José Giacomo BACCARIN² \\ Denise Boito Pereira da SILVA \\ Darlene Aparecida de Oliveira FERREIRA ${ }^{4}$ \\ Jonatan Alexandre de OLIVEIRA ${ }^{5}$
}

\section{Resumo}

O Artigo 14 da Lei $11.947 / 2009$ do Programa Nacional de Alimentação Escolar estabelece que, dos repasses federais para governos estaduais e municipais executarem ações de alimentação escolar, no mínimo 30\% devam ser gastos na compra de produtos de agricultores familiares. O primeiro objetivo é propor uma sistematização de diversas variáveis avaliativas dos resultados da execução do Artigo 14 . O segundo é usar parte dessas variáveis para analisar a ação das prefeituras municipais de São Paulo entre 2011 e 2014. Procura-se verificar se essa ação pública contribui com aumento da renda dos agricultores e o desenvolvimento local e com o acréscimo do uso de produtos in natura na alimentação escolar. Observou-se que as prefeituras aumentaram a compra de produtos da agricultura familiar de 2011 a 2014, pagando preços mais altos do que em mercados convencionais, priorizaram agricultores do município e a compra de produtos vegetais in natura. Em vários processos de compras foram constatadas lacunas, como a não informação do preço. O alcance do Artigo 14 é limitado quanto ao número e a renda dos agricultores familiares do Estado. Como aprimoramento propõe-se o desenvolvimento de outras ações de comercialização, maior integração entre as áreas públicas envolvidas e participação dos agricultores locais.

Palavras-chave: Agricultura familiar. Compras públicas. Alimentação escolar. Abastecimento.

\footnotetext{
${ }^{1}$ Agradece-se ao CNPq, Ministério do Desenvolvimento Social e Combate à Fome e Ministério de Ciência, Tecnologia e Informação pela concessão de recursos para projetos de pesquisa e extensão.

2 Professor Doutor da Faculdade de Ciências Agrárias e Veterinárias, UNESP, campus de Jaboticabal (SP). E-mail: baccarin@fcva.unesp.br

3 Mestre em Geografia, UNESP, campus Rio Claro (SP). E-mail: denise_bps@hotmail.com

${ }^{4}$ Professora Assistente Doutor MS2, UNESP, campus Rio Claro (SP). E-mail: darlene@rc.unesp.br

${ }^{5}$ Doutorando em Geografia, UNESP, campus Rio Claro (SP). E-mail: jonatan.sp@bol.com.br
} 


\section{Abstract}

\section{Public purchases of products from family farmers for school feeding in the state of São Paulo under federal law 1.947/2009}

The 14th Article of Law 11,947/ 2009 of the National School Feeding Programme establishes that from the federal transfers to states and municipal governments run school feeding activities at least $30 \%$ should be spent on the purchase of products from family farmers. The first objective is to propose a systematization of several evaluative variables from its execution results. The second is to use part of these variables to analyze the action of the municipalities of São Paulo from 2011 to 2014. It seeks to determine whether this public action contributes to increase the income of farmers and local development and the rise of the use of fresh products in school meals. It was noted that local governments increased the purchase of products from family farms from 2011 to 2014, paying higher prices than in conventional markets, prioritized local farmers and the purchase of fresh vegetal products. In several bidding processes gaps were discovered, such as the absence of the prices information. The reach of the 14th Article is limited regarding the number and income of family farmers in the state. As an improvement it is proposed to develop other commercialization actions, greater integration between public managers involved and the participation of local farmers.

Key words: Family farming. Public procurement. School feeding. Food provision.

\section{INTRODUÇÃO}

Em 2003 foi aprovada a Lei Federal 10.696 (BRASIL, 2003), dando origem ao Programa de Aquisição de Alimentos da Agricultura Familiar (PAA) no Brasil, ação prevista na execução do Programa Fome Zero. Tinha-se o propósito de garantir a compra, por preços mais altos do que os de mercados tradicionais, de produtos alimentícios de agricultores familiares para destiná-los ao consumo de pessoas em insegurança alimentar. Desde o início, destinou-se parte significativa das aquisições do PAA à alimentação escolar gerenciada por governos estaduais e prefeituras municipais.

Mais adiante, em junho de 2009, foi aprovada a Lei Federal 11.947 (BRASIL, 2009) que regulamenta o Programa Nacional de Alimentação Escolar (PNAE), vigente desde 1955, mas que ainda não tinha uma lei geral a lhe consolidar. Uma das orientações da nova Lei é assegurar maior qualidade nutricional na alimentação escolar, substituindo, por exemplo, alimentos muito processados por produtos in natura, como frutas, legumes e verduras. De pronto, isso abre espaço para maior participação de agricultores familiares como fornecedores de alimentação escolar, por terem grande participação na produção desses produtos.

E a Lei 11.947 acaba por formalizar essa possibilidade, em seu Artigo 14, ao determinar que, do total de recursos financeiros repassados pelo Fundo Nacional de Desenvolvimento da Educação (FNDE) aos estados e municípios para gastos na alimentação escolar, no mínimo 30\% devam ser utilizados na aquisição de gêneros alimentícios oriundos de agricultores familiares ou de suas organizações.

O Artigo 14, institucionalmente falando, pode ser considerado como uma derivação do PAA, indo adiante no que se refere ao comprometimento orçamentário. No PAA, não há vinculação orçamentária previamente definida, enquanto o Artigo 14 se apresenta de forma mais incisiva, estabelecendo porcentagem obrigatória mínima de 
aplicação dos recursos repassados pelo FNDE aos entes da federação que executam ações de alimentação escolar.

Na regulamentação da Lei 11.947, pela Resolução no 38 de 2009, instituiu-se a Chamada Pública como instrumento para aquisição dos produtos da agricultura familiar, em vez dos instrumentos tradicionais de licitação pública, da Lei 8.666/1993 (BRASIL, 1993). Levando-se em conta que se pretende garantir preços mais justos aos agricultores familiares, a chamada pública, a partir de alguns critérios, deve fixá-los previamente e os mesmos não devem ser objeto de eventual disputa entre os agricultores familiares para fornecerem para alimentação escolar. Outros quesitos devem ser usados na escolha dos agricultores fornecedores.

Assim, estabelece-se que, preferencialmente, deva-se comprar de agricultores locais; na impossibilidade disso, de agricultores do território rural; seguido por agricultores do estado e; por fim, caso necessário, de agricultores de outros estados (Resolução do FNDE no 4, 2015). Com isso, procura-se trabalhar com a movimentação local dos recursos públicos recebidos e com os circuitos curtos de comercialização, mesmo porque isso se mostra mais adequado ao incentivo do consumo de produtos in natura, normalmente muito perecíveis. Assegura-se também que terão prioridade os assentados da Reforma Agrária, quilombolas e indígenas, os que produzem de forma orgânica/agroecológica e os organizados em associações ou cooperativas.

Sabe-se que a alimentação escolar é um direito constitucional e, portanto, se estabelece como política permanente de Estado. A Lei 11.947, ao regulamentar esse direito, vinculou formalmente a alimentação escolar ao aumento de renda da agricultura familiar, vínculo esse que se associa às concepções de estímulo ao desenvolvimento local e de melhoria da qualidade nutricional no consumo dos alunos atendidos, à medida que contribua com a substituição de produtos muito processados por aqueles in natura.

Até por que tal legislação é bastante nova, passando a ser implantada em 2010, é importante que se realizem diversos estudos para medir sua efetividade e eficácia, o que, aliás, já vem ocorrendo em várias regiões do País. Citem-se, nesse sentido, trabalhos de Costa et al (2015) para Minas Gerais, Souza-Esquerdo e Bergamasco (2014), Baccarin et al (2011) e Baccarin et al (2012) para São Paulo, Braga e Azevedo (2012) e Marques et al (2014) para Ceará, Silva e Souza (2013) para Santa Catarina, Bohner et al (2014) para o Rio Grande do Sul, entre outros.

Além da leitura crítica desses e outros estudos, os autores do presente artigo acumularam informações e interpretações em ações de pesquisas e extensão acadêmicas $^{6}$, como seminários e capacitações, a partir da consulta a documentos públicos e entrevistas/contatos com atores sociais envolvidos na aplicação do Artigo 14.

\footnotetext{
6 Entre 2010 e 2013 aprovou-se três projetos de pesquisa e/ou extensão junto ao Conselho Nacional de Pesquisa e Desenvolvimento Tecnológico (CNPq). O primeiro, vigente de 2010 a 2012, "Reconhecimento e Gestão de Políticas Públicas de Segurança Alimentar: o Caso do Programa de Aquisição de Alimentos da Agricultura Familiar e da Implantação da Lei 11.947 no Estado de São Paulo", contemplado com recursos da "Chamada MCTI-SECIS/CNPq, número 019/2010, com Propostas de Pesquisa em Tecnologias Sociais em Segurança Alimentar e Nutricional". O segundo, de 2013 a 2015, "Agricultura Familiar sob a Vigência da Lei Federal 11.947/2009: Abrangência e Adequação das Chamadas Públicas, Impactos na Agricultura Local e Preços Recebidos pelos Agricultores Familiares", contemplado com recursos da "Chamada MCTI-CNPq/MDS-SAGI, número 24/2013, Desenvolvimento Social". O terceiro, em execução desde 2013, "Efeitos das Compras Institucionais via Programa de Aquisição de Alimentos e Programa Nacional de Alimentação Escolar nas Condições de Vida de Agricultores Familiares e no Desenvolvimento Local: Estudo e Aplicação em três Regiões do Estado de São Paulo e Articulações com Países da UNASUL", contemplado com recursos da "Chamada MCTI/Ação Transversal - LEI/CNPq No 82/2013 Segurança Alimentar e Nutricional no Âmbito da UNASUL e África".
} 
A partir disso, pretende-se, como primeiro objetivo do artigo, propor uma sistematização de diversas variáveis que contribuam para avaliação da aplicação local, especialmente pelos municípios, do Artigo 14 da Lei 11.947. O segundo objetivo é avaliar parte dessas variáveis para o estado de São Paulo de 2010 a 2014, procurando-se verificar como o Governo Estadual e, especialmente, as prefeituras municipais têm implantado a nova legislação, como tem se dado a participação dos agricultores familiares e, ainda que parcialmente, como o processo influencia no fortalecimento da agricultura familiar e no desenvolvimento local e na melhoria da qualidade nutricional da alimentação escolar. Cada um dos objetivos relaciona-se com uma das duas seções apresentadas a seguir e o artigo encerra-se com algumas considerações finais.

\section{PROPOSTA DE AVALIAÇÃO DAS DIFICULDADES, POSSIBILIDADES E ALCANCE DO ARTIGO 14}

A aplicação do Artigo 14 pressupõe importantes (e desafiadoras) mudanças na execução de uma relativamente antiga ação de segurança alimentar e nutricional, a alimentação escolar. De parte do agente público, local ou regional, que a gerencia, espera-se que promova alterações no cardápio, com a incorporação de produtos que podem exigir maior manipulação no preparo das refeições, e nos processos licitatórios para compra de produtos para alimentação escolar. Por seu lado, o agricultor familiar se defronta com diversas questões ligadas à formalidade jurídica e à capacidade de associação, bem como às características de sua produção, como regularidade, sanidade e necessidades de transformações, ainda que pequenas, em seus produtos.

Procura-se organizar, a seguir, essas e outras questões em quatro tópicos, destacando-se justamente os papéis dos gestores públicos da alimentação escolar e dos agricultores familiares.

\section{Papel das Prefeituras Municipais e Governos Estaduais}

Inicialmente, convém tecer breves comentários sobre o papel das esferas de governo na gestão da alimentação escolar. Em 1994, o Governo Federal passou a descentralizar os seus recursos financeiros para estados e municípios gerirem as ações administrativas, licitatórias e de fornecimento de alimentação aos escolares sob sua jurisdição. É comum que às verbas vindas da União, repassadas pelo FNDE, estados e municípios acrescentem recursos próprios para a compra de produtos alimentícios, além de garantirem a estrutura física e funcionários para a execução da ação. A descentralização de atividades contribui para reduzir custos logísticos e administrativos e potencializar o controle social, já que todas as Entidades Executoras (EEs) do PNAE devem constituir o Conselho de Alimentação Escolar (CAE)

Os municípios podem ficar responsáveis pelo fornecimento da alimentação escolar também às escolas estaduais situadas em seu território, como sói acontecer em São Paulo. Assim, dos R\$ 640,7 milhões repassados em 2014 pelo FNDE para alimentação escolar de alunos paulistas, $\mathrm{R} \$ 507,3$ milhões $(79,2 \%)$ foram recebidos pelas prefeituras e $R \$ 133,4$ milhões $(20,8 \%)$ pela Secretaria Estadual de Educação do Governo do Estado de São Paulo (FNDE, 2015).

Quanto aos governos estaduais, sugere-se que um ponto específico 14 seja avaliado, qual seja a forma como as compras ocorrem, se centralizadas ou distribuídas regionalmente ou mesmo em nível das escolas. Em se centralizando as compras, 
entende-se que a participação dos agricultores familiares individualmente ou através de pequenas associações/cooperativas seria mais difícil e beneficiar-se-iam estruturas mais fortes financeiramente, como grandes cooperativas, com DAP (Declaração de Aptidão ao Programa Nacional de Fortalecimento da Agricultura Familiar - Pronaf) jurídica.

Daqui por diante, as discussões estão mais relacionadas às ações das prefeituras municipais, embora também possam ser usadas para a avaliação da atuação das secretarias estaduais de educação.

Como já afirmado, a execução das compras relativas ao Artigo 14 se faz via chamadas públicas, com preços dos produtos fixados previamente, e devendo-se conceder, no mínimo, 20 dias entre seu anúncio e a escolha dos ganhadores. Também já se afirmou que, na necessidade de desempate, devem-se priorizar, nessa ordem, agricultores do município, fornecedores de origem indígena, quilombola ou de assentamentos de Reforma Agrária, produtos orgânicos/agroecológicos e agricultores organizados em associações ou cooperativas. Por ser aparentemente simples, pode-se supor, em princípio, que esse tipo de certame de compras seria de mais fácil execução do que as licitações convencionalmente praticadas pelos municípios.

Contudo, devem ser levadas em conta as adaptações necessárias nas ações das prefeituras municipais. Grande parte delas, tradicionalmente, organizava suas compras de alimentos via licitações com participação de empresas fornecedoras especializadas, normalmente não localizadas no município e que ofereciam, no mais das vezes, produtos com considerável grau de processamento, facilmente armazenáveis e exigindo pouca manipulação por parte das funcionárias encarregadas do preparo da refeição escolar. Ao grosso das compras, feito dessa forma, as prefeituras podiam adicionar produtos comprados localmente, como panificados e legumes e verduras, especialmente.

Um ponto chave para verificar a adequação das prefeituras ao Artigo 14 são as eventuais modificações no cardápio da alimentação escolar, adaptando-o às condições produtivas dos agricultores familiares. Deve-se considerar, contudo, que nem toda modificação recente teve esse propósito, mas muitas foram consequências dos maiores cuidados com a qualidade nutricional que os serviços municipais passaram a revelar de alguns anos para cá, inclusive com a obrigatoriedade de se contar com profissional de nutrição na equipe de alimentação escolar a partir de 2006 (Resolução FNDE 32/2006).

Mesmo havendo vontade, deve-se levar em conta que existem barreiras sanitárias e tecnológicas que dificultam a compra direta de produtos da agricultura familiar, especialmente os de origem pecuária. Ovos e mel podem ser comprados sem maiores transformações, mas os diversos tipos de carne e leite devem, necessariamente, ser processados em agroindústrias, frigoríficos e laticínios, não se visualizando a possibilidade de que prefeituras montem esquemas próprios de pasteurização, uperização (para leite longa vida) ou de abate de animais.

Entretanto, sobram várias possiblidades das prefeituras abrirem espaço para os produtos de agricultores familiares, comprando produtos in natura ou com baixo nível de processamento, como arroz, feijão e uma série de legumes, verduras e frutas frescas diretamente dos agricultores familiares. Pode-se supor, inclusive, que as prefeituras adquiram pequenos maquinários e equipamentos para extração de suco de frutas como abacaxi e laranja, esta última muito importante na agricultura do estado de São Paulo.

Uma maneira de se verificar o comprometimento das prefeituras com esse ponto é analisar o grau de processamento dos produtos que são solicitados nas chamadas publicas. Nesse sentido, sugere-se que, adaptando-se a proposta de Monteiro 
et al. (2010), incluindo-se produtos in natura, os alimentos sejam classificados em: i) produtos in natura, que não passam por nenhum processamento; ii) com mínimo grau de processamento, que passam apenas por transformações físicas; iii) médio grau de processamento, com transformações físico-químicas; iv) alto grau de processamento, com transformação industrial fora do espaço produtivo do agricultor familiar. A suposição que se estabelece é que quanto menor o grau de processamento exigido, mais adaptadas as chamadas públicas estariam às condições dos agricultores familiares.

Um comprometimento maior das prefeituras com os agricultores e o desenvolvimento local se evidenciaria ao se promoverem modificações no cardápio para contemplar alimentos produzidos no próprio município ou na região, inclusive considerando sua sazonalidade. Alguns exemplos podem ser citados, com a substituição de fontes de carboidratos, pão por mandioca ou batata inglesa, a incorporação de peixe na alimentação escolar em regiões com piscicultura desenvolvida, o uso de mel em lugar do açúcar da cana etc.

Desse ponto deriva algo mais desafiador e de difícil implantação (aliás, não só para o programa aqui analisado), que seria a integração de diferentes setores públicos, no caso em análise, da alimentação escolar e de fomento agropecuário, não esquecendo as mudanças nos trâmites administrativos. Além da adaptação do cardápio às condições locais, pode-se imaginar a realização de outras ações públicas, como capacitações dos agricultores sobre a nova legislação, necessidade de atender normas sanitárias e ter regularidade de entrega de seus produtos, questões de formalização e estímulo ao associativismo, à produção de produtos alternativos ou à realização de investimentos para pequenas transformações dos produtos pelos próprios agricultores.

Outro ponto a ser considerado diz respeito à periocidade e ao número de pontos de entrega dos produtos. Atualmente, em 2015, o agricultor pode incluir o custo do transporte no limite de $\mathrm{R} \$ 20$ mil que pode receber de cada entidade executora do PNAE, mas ao fazer isso, ele acaba por vender menor quantidade de sua produção. Nesse sentido, prefeituras que centralizem o recebimento dos alimentos beneficiam mais a agricultura familiar do que as que determinam a entrega muito descentralizada, por exemplo, em todas as unidades em que são servidas refeições escolares. De forma semelhante, a obrigatoriedade de entrega de produtos várias vezes por semana prejudica a participação dos agricultores.

Sugere-se que a periodicidade de entrega seja classificada em: i) entregas 25 vezes/semana; ii) semanais; iii) 1-2 vezes/mês; iv) entregas esporádicas, algumas vezes no ano; v) não consta a informação. Em relação aos pontos de entrega as chamadas podem ser classificadas em: i) centralizadas, com uma única unidade de recebimento (UR); ii) pouco descentralizadas, entre 2 e 10 UR; iii) descentralizadas, entre 11 e 50 UR; iv) muito descentralizadas, com mais de 50 UR; v) não consta a informação.

Por fim, mas não menos importante, deve-se fazer uma avaliação quantitativa do cumprimento do Artigo 14 pelas prefeituras. O agrupamento de prefeituras proposto, de acordo com o percentual de compra de produtos da agricultura familiar em relação aos repasses do FNDE, é o seguinte: i) refratárias ao Artigo 14 - não adquirem nada dos agricultores familiares; ii) pouco aderentes - adquirem entre $0,1 \%$ e $10,0 \%$; iii) medianamente aderentes - as porcentagens ficam entre $10,1 \%$ e $25 \%$; iv) aderentes - os gastos ficam entre $25,1 \%$ e $35 \%$; iv) altamente aderentes - gastam além dos $35,1 \%$ dos repasses do $\mathrm{FNDE}$, podendo chegar a $100 \%$ ou mesmo mais, se incorporarem recursos de outras origens federativas, do estado ou do próprio município.

Parte dos quesitos acima apontados deve ser levantada através de entrevistas e questionários aplicados aos agentes públicos e sociais envolvidos com o Artigo 14. 
Outra parte, mais significativa, pode ser obtida em documentos, com destaque para as chamadas públicas, muitas vezes disponíveis em sites das prefeituras municipais. Sua qualidade dependerá da boa descrição dos produtos pretendidos, da explicitação dos preços e dos critérios de desempate, de informações sobre periodicidade e pontos de entrega, da forma como ocorre a divulgação e da criação de rotinas que possibilitem aos agricultores saberem quando as chamadas são lançadas.

Além das chamadas públicas, outros dois tipos de documentos podem ser acessados. Um deles é a prestação de contas que cada prefeitura, anualmente, deve encaminhar ao FNDE sobre a execução do PNAE, com ponto específico relativo ao Artigo 14, que pode ser encontrado no site do FNDE. Até o final do primeiro semestre de 2015, o FNDE disponibilizava esse documento apenas após sua avaliação final, 0 que costuma demorar anos. Em setembro de 2015, o FNDE disponibilizou, ainda que preliminarmente (posto que a maior parte da análise não terminou) todas as prestações de contas de prefeituras municipais e secretarias estaduais de educação dos anos de 2011 a 2014. As de 2013 e 2014 trazem, inclusive, detalhamento das notas fiscais, com preços e produtos efetivamente comprados, além dos dados do fornecedor.

Outro tipo de documento que se pode acessar, tendo que se obtê-lo diretamente com as prefeituras, são os contratos estabelecidos com os agricultores familiares ou suas organizações para fornecimento dos produtos contidos nas chamadas públicas de que foram vencedores. Esses contratos servem para confirmar se os quesitos das chamadas públicas são cumpridos e traz o endereço do agricultor ou de sua organização, permitindo verificar se a compra está sendo feita no município, na região, no estado ou fora do estado. Afirme-se que definir a abrangência da região não é simples e os autores desse artigo a consideram, sem maior rigor analítico e por sugestão de agricultores familiares, como composta por todos os municípios em um raio de até $100 \mathrm{Km}$ da sede do município executor do PNAE.

\section{Atratividade para os Agricultores Familiares}

O estímulo para que os agricultores familiares participem, como fornecedores do PNAE, depende do alcance do programa em relação ao seu número e renda bruta. Há expectativa de se obterem preços mais altos, mas cujos efeitos sobre a renda dos agricultores podem ser insuficientes para sua adesão ao programa, mesmo por que há a necessidade de se realizar uma série de adaptações produtivas e formais em seus estabelecimentos agropecuários.

A atratividade de participação como fornecedor de produtos para a alimentação escolar pode ser abordada para o conjunto de agricultores familiares ou para um agricultor isoladamente. No primeiro caso, considera-se que municípios com maiores populações e mais alunos são mais atrativos, pois os valores a serem gastos na compra de produtos da agricultura familiar, em termos absolutos, seriam bem mais expressivos. Inclusive, municípios muito grandes e pertencentes a regiões metropolitanas podem ter área rural insignificante, fazendo-os demandar produtos de outros municípios.

\footnotetext{
7 Nas resoluções do FNDE fala-se em territórios rurais, que são os Territórios da Cidadania, com conformação definida pelo Ministério do Desenvolvimento Agrário. Não é essa conotação que aqui se está dando ao termo região. Não se deve esquecer que os territórios da cidadania estão muito longe de abranger todo o território brasileiro, restando muitos municípios fora de seus limites.
} 
A sugestão é que se procure confrontar o repasse do FNDE destinado à alimentação escolar para o município ou estado com a renda da agricultura familiar daquele local, que está disponível para 2006, ano de realização do último Censo Agropecuário. Dando um passo adiante, podem-se verificar relações mais específicas, do consumo na alimentação escolar e da produção local de determinados produtos, como arroz, feijão, leite e outros mais.

Para o agricultor, sua participação é estimulada pelo valor que arrecade no ano vendendo para a alimentação escolar. No início, previa-se que cada um podia vender no máximo até R\$ 9 mil por ano (Resolução FNDE no 38, 2009), valor que passou para R\$ 20 mil em 2012, considerando-se o conjunto de entes públicos executores da alimentação escolar (Resolução FNDE n 25, 2012). Desde 2015, esse limite manteve-se em $R \$ 20$ mil, mas passou a ser relacionado a cada entidade executora (Resolução FNDE n4, 2015). Ou seja, um agricultor familiar, atualmente, pode alcançar ganhos muito maiores, desde que forneça para mais de um município.

Essas mudanças merecem discussão específica, à medida que podem beneficiar mais determinados agricultores ou suas organizações, mas limite a participação de maior número deles. Sugere-se que, ao longo dos próximos anos, tente-se avaliar se isso fez com que se diminuísse o número de agricultores familiares participantes do Artigo 14 e se as compras se concentraram em associações e cooperativas relativamente grandes. Para efeitos comparativos, pode-se usar o número de agricultores familiares registrados pelo Censo Agropecuário de 2006.

\section{Capacidade de Participação dos Agricultores}

Inicialmente, é importante que se levantem características sociais e estruturais dos agricultores familiares da região ou estado a que pertencem. Supõe-se que, em locais em que a agricultura familiar tenha maior expressão econômica, com agricultores mais integrados aos mercados e com maior capacidade de associação, entre outras características, sua capacidade de fornecimento no âmbito do Artigo 14 seja maior.

Embora o processo seja simplificado, é necessário o atendimento de questões burocráticas e legais para os agricultores participarem do PNAE, como dispor de Nota do Produtor e ser reconhecido formalmente como agricultor familiar através da DAP. Sugere-se comparar o número de agricultores com DAP com o número de agricultores familiares do município, conforme o Censo Agropecuário de 2006. O acesso a outros programas públicos, como o PAA e o Pronaf, também pode ser um fator de estímulo à participação no PNAE e, portanto, convém ser levantado.

Em princípio, pode-se supor que a participação dos agricultores seria facilitada se os mesmos integrassem entidades coletivas, associações e cooperativas, dandoIhes maior possibilidade de acompanhamento das chamadas públicas e de atendimento às questões burocráticas, não comprometendo suas atividades essencialmente agrícolas, fato muitas vezes desconsiderado em várias análises.

Contudo, tal suposição pode não se confirmar, caso a associação ou cooperativa, de fato, não aja como representante do agricultor, mas se constitua em mero intermediário na comercialização de seu produto, não the repassando os preços mais altos obtidos na alimentação escolar. Para aferir isso é necessário se obter informações diretamente dos agricultores familiares, bem como estudar a forma como atuam aquelas organizações, em especial como se relacionam com seus associados ou cooperados.

Um ponto já comentado deve ser aqui reforçado, qual seja a capacidade dos agricultores processarem seus produtos e aumentarem a participação na alimentação 
escolar. Pode-se pensar em processamento mais simples, como a higienização, o descascamento e corte e a embalagem de legumes e verduras, ou pouco mais complexo, que requereria a instalação de pequena agroindústria artesanal. Em muitos dos casos, seria necessária a realização de investimentos produtivos, nem sempre efetiváveis levando em conta as condições financeiras dos agricultores e as exigências normativas fiscais, sanitárias e ambientais para a instalação de agroindústria.

Uma última, mas muito importante questão, diz respeito à coincidência entre calendário agrícola e o escolar. Especialmente para os produtos perecíveis, os produtos da agricultura familiar devem estar disponíveis naqueles momentos em que, na programação do cardápio, comporiam as refeições escolares. Já se comentou as iniciativas que a gestão municipal pode fazer para aumentar essa coincidência, mas tal fato pode ser reforçado pela reprogramação, ao longo do ano, das atividades agropecuárias pelos agricultores, não se olvidando das dificuldades que isso impõe.

\section{Preços Praticados}

Especificou-se essa discussão para reforçar o óbvio e duplo significado do preço praticado, como gasto público e renda para os agricultores familiares. Ao realizar suas compras, estabelecida a qualidade requerida, as prefeituras devem procurar obter a maior quantidade possível de produtos alimentícios, ou seja, pagar menores preços. Por seu lado, o incentivo ao agricultor para participar do PNAE se daria com o recebimento de preços acima dos obtidos nos mercados convencionais.

Isso não necessariamente é incompatível. Basta entender que a compra pelo Artigo 14 é direta dos agricultores familiares ou de suas organizações, com seus produtos podendo ser remunerados pelas prefeituras ao nível dos preços praticados no varejo ou atacado em que tradicionalmente se realizam compras para a alimentação escolar. Pela compra direta e, muitas vezes, em canais mais curtos, seria diminuída a margem de comercialização, garantindo-se maiores preços aos agricultores familiares.

Na fixação de preços, as prefeituras devem obedecer alguns critérios. Os preços deverão ser pesquisados em três mercados locais, inclusive, na feira do agricultor familiar, se possível. Se este levantamento não puder ser feito localmente, deverá ser feito em âmbito territorial, estadual ou nacional, nesta ordem de prioridade. Os preços também devem ser acrescidos de eventuais gastos com embalagens, transporte, encargos que o agricultor possa vir a ter. No caso de produtos orgânicos, caso não haja possibilidade de se pesquisar o seu preço, deve-se levantar os preços dos produtos tradicionais e acrescer o seu valor em 30\% (Resolução FNDE no 4, 2015).

O estudo da adequabilidade dos preços constantes das chamadas públicas, para produtos in natura, é possível via sua comparação com preços pagos ao produtor agropecuário em mercados convencionais, registrados por órgãos públicos de economia agrícola, existentes em vários estados. Também é possível a comparação com preços no atacado, tomando por base informações de centrais públicas de abastecimento de hortigranjeiros. As dificuldades seriam maiores no caso dos produtos processados, sugerindo-se a comparação com informações oriundas de pesquisas sistemáticas visando compor índices de inflação ou com preços praticados nas licitações tradicionais (no âmbito da Lei 8.666) para o PNAE.

Convém reforçar a percepção que o diferencial de preços entre os mercados convencionais em que os agricultores vendem seus produtos e aqueles (mais altos, supostamente) obtidos no fornecimento para a alimentação escolar via Artigo 14 pode estimular comportamentos oportunistas de alguns agentes sociais. Já se afirmou a possiblidade de cooperativas ou associações reterem para si esse diferencial, não o 
repassando para os agricultores. Contudo, há outras possibilidades, como a de se forjar a situação de agricultor familiar, através do "aluguel" ou uso indevido do número de DAP e mesmo da comercialização de produtos não originários da agricultura familiar, mas comprados em centrais de abastecimento, por exemplo.

\section{APLICAÇÃO DO ARTIGO 14 NO ESTADO DE SÃo PAULO}

Apresentam-se alguns resultados com base, especialmente, nos projetos de pesquisa/extensão citados na introdução. Os dados e informações foram obtidos em diferentes momentos e amostras e, portanto, não estão estritamente relacionados e não constituem um objeto de análise único. Contudo, entende-se que os resultados refletem com muita aderência o que vem se dando na implantação do Artigo 14 em São Paulo.

\section{Ações das Prefeituras Municipais - Características das Chamadas Públicas}

Em 2014 consultaram-se sites de prefeituras de São Paulo, à procura de chamadas públicas de 2012 e 2013. Coletaram-se 197 chamadas de 161 municípios (um município pode lançar mais de uma chamada por ano) em 2012 e, 212 chamadas de 156 municípios em 2013. Essas 409 chamadas permitiram as análises a seguir.

\section{Origem dos Produtos}

A tabela 1 revela a presença de produtos de origem animal ou vegetal nas chamadas públicas ${ }^{8}$. Observa-se que a maior parte dos editais contém produtos de origem vegetal. Isto demonstra adequação às condições dos agricultores familiares, já que as normas sanitárias da produção animal são mais rigorosas e demandam maiores recursos financeiros para serem cumpridas. Os produtos de origem vegetal constituíram a imensa maioria, $95,0 \%$ a $96,0 \%$, dos itens relacionados nas chamadas públicas.

Tabela 1 - Quantidade de chamadas públicas com produtos de origem animal ou vegetal e quantidade de produtos de origem animal ou vegetal nas chamadas públicas, municípios de São Paulo, 2012 e 2013

\begin{tabular}{c|cc|cc|rr|rr}
\hline \multirow{2}{*}{$\begin{array}{c}\text { Origem } \\
\text { do }\end{array}$} & \multicolumn{4}{|c|}{ Quantidade de Chamadas } & \multicolumn{3}{c|}{ Quantidade de produtos } \\
\cline { 2 - 9 } Produto & 2012 & \multicolumn{2}{|c|}{2013} & \multicolumn{2}{c|}{2012} & \multicolumn{2}{c}{2013} \\
\cline { 2 - 9 } & No. & $\%$ & No. & $\%$ & No. & \multicolumn{1}{c}{$\%$} & No. & $\%$ \\
\hline Animal & 110 & 55,8 & 118 & 55,7 & 216 & 5,0 & 191 & 4,0 \\
Vegetal & 193 & 98,0 & 204 & 96,2 & 4.060 & 95,0 & 4.525 & 96,0 \\
\hline
\end{tabular}

Fonte: Baccarin et al, 2015.

\footnotetext{
8 Nesse caso, a soma dos dois itens resulta em mais de $100 \%$, posto que uma mesma chamada pode conter tanto produtos de origem vegetal como animal. Com outros dados, algo semelhante pode ter acontecido.
} 


\section{Grau de Processamento}

Na tabela 2 pode-se notar, tanto na presença como no número de itens, que ocorre ampla prevalência de produtos in natura nas chamadas. Aqui também se verifica adequação às condições de agricultores familiares menos capitalizados. Como se verá adiante, os produtos com maior grau de processamento, em grande parte, foram fornecidos por grandes cooperativas de agricultores familiares do Rio Grande do Sul.

\section{Tabela 2 - Presença e quantidade de produtos com diferentes graus de processamento nas chamadas públicas, municípios de São Paulo, 2012 e 2013}

\begin{tabular}{l|rr|rr|rr|rr}
\hline \multirow{2}{*}{$\begin{array}{c}\text { Nível } \\
\text { de }\end{array}$} & \multicolumn{3}{|c|}{ Quantidade de Chamadas } & \multicolumn{3}{c}{ Quantidade de produtos } \\
\cline { 2 - 9 } Processam. & \multicolumn{2}{|c|}{2012} & \multicolumn{2}{c|}{2013} & \multicolumn{2}{c}{2012} & \multicolumn{2}{c}{2013} \\
\cline { 2 - 9 } & \multicolumn{1}{|c|}{ No. } & $\%$ & No. & $\%$ & No. & $\%$ & No. & $\%$ \\
\hline In natura & 172 & 87,3 & 174 & 82,1 & 3.877 & 89,2 & 4.318 & 88,8 \\
Mínimo & 87 & 44,2 & 124 & 58,5 & 184 & 4,2 & 218 & 4,5 \\
Médio & 59 & 30,0 & 92 & 43,4 & 159 & 3,7 & 187 & 3,8 \\
Alto & 53 & 26,9 & 50 & 23,6 & 127 & 2,9 & 140 & 2,9 \\
\hline
\end{tabular}

Fonte: Baccarin et al, 2015.

\section{Periodicidade e Pontos de Entrega}

Percebe-se na tabela 3 que muitos editais não traziam informações sobre a periodicidade de entrega dos alimentos, o que é uma falha importante, considerandose que esta informação é vital para o planejamento e decisão do agricultor familiar.

\section{Tabela 3 - Periodicidade e número de unidades de entrega de produtos nas chamadas públicas, municípios de São Paulo, 2012 e 2013}

\begin{tabular}{|c|c|c|c|c|c|c|c|c|c|}
\hline \multirow{3}{*}{$\begin{array}{l}\text { No. de } \\
\text { vezes }\end{array}$} & \multicolumn{4}{|c|}{ Periodicidade de Entrega } & \multirow{3}{*}{$\begin{array}{l}\text { No. de } \\
\text { unid. }\end{array}$} & \multicolumn{4}{|c|}{ Unidades de Recebimento } \\
\hline & \multicolumn{2}{|c|}{2012} & \multicolumn{2}{|c|}{2013} & & \multicolumn{2}{|c|}{2012} & \multicolumn{2}{|c|}{2013} \\
\hline & No. & $\%$ & No. & $\%$ & & No. & $\%$ & No. & $\%$ \\
\hline 2-5/sem & 16 & 7,5 & 20 & 8,7 & 1 & 97 & 49,2 & 109 & 51,4 \\
\hline Semanal & 81 & 38,0 & 81 & 35,1 & 2 a 10 & 20 & 10,2 & 15 & 7,1 \\
\hline $1-2 /$ mês & 15 & 7,0 & 17 & 7,4 & 11 a 50 & 31 & 15,7 & 49 & 23,1 \\
\hline Esporád. & 2 & 1,0 & 26 & 11,2 & mais 50 & 7 & 3,6 & 8 & 3,8 \\
\hline$\tilde{N}$ cons. & 99 & 46,5 & 87 & 37,7 & $\tilde{N}$ cons. & 44 & 22,3 & 30 & 14,2 \\
\hline
\end{tabular}

Fonte: Baccarin et al, 2015.

Nos editais em que essa informação aparecia, prevaleceu a entrega semanal, que é compatível com as condições dos agricultores familiares e com a compra de vegetais in natura, que são os itens mais pedidos. A entrega mais de uma vez por semana se torna muito onerosa para os agricultores familiares. As entregas mais esporádicas estão relacionadas, no mais das vezes, com produtos não perecíveis.

Ainda a tabela 3 aponta o número de unidades de recebimento presentes nos editais. A entrega centralizada aparece em aproximadamente metade dos editais de São Paulo, o que favorece ao agricultor familiar, pois reduz as despesas com frete dos produtos. Embora com menor intensidade, também nesse quesito um número considerável de editais não apresentava essa informação. 


\section{Ações das Prefeituras Municipais - Origem dos Agricultores Familiares}

Para obter o endereço dos agricultores ou suas organizações, foram consultados 128 contratos de fornecimento de alimentos pelos agricultores familiares de 2012 e 2013 para 22 municípios de São Paulo?.

A tabela 4 mostra que a maior parte das prefeituras tinha contratos com agricultores do próprio município ou em municípios distantes até 100 quilômetros (regional). Em 2013, apenas seis prefeituras optaram por comprar produtos de outros estados (Paraná, Santa Catarina e Rio Grande do Sul).

\section{Tabela 4 - Local do estabelecimento dos agricultores familiares fornecedores de alimentos para prefeituras de São Paulo, 2012 e 2013}

\begin{tabular}{l|cc|c|c|c|c}
\hline \multirow{2}{*}{ Local do } & \multicolumn{2}{|c|}{2012} & \multicolumn{2}{c|}{2013} & \multicolumn{2}{c}{ Total } \\
\cline { 2 - 8 } Estabelecimento & Número & $\%$ & Número & $\%$ & Número & $\%$ \\
\hline Municipal & 10 & 66,7 & 12 & 57,1 & 14 & 63,6 \\
Regional & 11 & 73,3 & 17 & 81,0 & 17 & 77,3 \\
Estadual & 4 & 26,7 & 7 & 33,3 & 8 & 36,4 \\
Outro estado & 2 & 13,3 & 6 & 28,6 & 6 & 27,3 \\
\hline
\end{tabular}

Fonte: Baccarin et al, 2015.

Os produtos fornecidos do próprio estado englobavam produtos in natura como legumes, verduras, frutas e ovos, principalmente, bem como alguns processados como vegetais minimamente processados, mel, doce de banana, bebida láctea, iogurte, queijos e suco de laranja. Santa Catarina fornecia maçã, Paraná arroz parbolizado e queijo e o Rio Grande do Sul apresentava extensa lista, com muitos produtos muito processados: arroz, barra de cereal, bebida láctea, biscoitos, doce de leite, farinha de milho, feijão, leite em pó, macarrão, mel, óleo de soja e suco de uva.

A tabela 5 mostra que, em termos financeiros, o volume gasto pelas 22 prefeituras paulistas foi destinado em sua maior parte, acima de $80 \%$, para agricultores do próprio Estado. Contudo, esse valor reduziu-se entre 2012 e 2013, quando o município de São Paulo começou a executar o Artigo 14. O Rio Grande do Sul, embora mais distante, aparece como o segundo estado com agricultores fornecedores para as prefeituras paulistas. Fora da Região Sul, nenhum outro estado contribuiu para o cumprimento do Artigo 14 em São Paulo.

Uma informação adicional é que os produtos com alto grau de processamento foram contratados exclusivamente de cooperativas (algumas de porte grande) e não de agricultores individuais ou associações.

\footnotetext{
${ }^{9}$ A relação desses municípios, acompanhados de respectivas faixas populacionais, é a seguinte: Alumínio, Capela do Alto, Divinolândia e Dolcinópolis (até 20 mil habitantes); Araçoiaba da Serra, Espírito Santo do Pinhal, Iperó, Jaboticabal, Jales, Matão, Monte Alto e Valparaíso (de 20 mil a 100 mil habitantes); Araraquara, Itapetininga, Piracicaba, Sertãozinho e Taboão da Serra (de 100 mil a 500 mil habitantes) e; Campinas, Ribeirão Preto, Santo André, São Paulo e Sorocaba (mais de 500 mil habitantes).
} 


\section{Tabela 5 - Valor dos contratos entre prefeituras paulistas e agricultores familiares, de acordo com seu estado de origem, 2012 e 2013, em mil reais}

\begin{tabular}{l|rr|rr|rr}
\hline \multirow{2}{*}{ Estado de Origem } & \multicolumn{2}{|c|}{2012} & \multicolumn{2}{|c|}{2013} & \multicolumn{2}{c}{ Total } \\
\cline { 2 - 7 } & Número & $\%$ & Número & $\%$ & Número & $\%$ \\
\hline Paraná & 0 & 0,0 & $1.659,5$ & 6,8 & $1.659,5$ & 5,7 \\
Rio Grande do Sul & 262,8 & 5,7 & $2.185,0$ & 8,9 & $2.447,8$ & 8,4 \\
Santa Catarina & 0 & 0,0 & 341,2 & 1,4 & 341,2 & 1,2 \\
São Paulo & $4.450,6$ & 94,4 & $20.338,7$ & 82,9 & $24.789,3$ & 84,8 \\
Total & $4.713,4$ & 100,0 & $24.524,4$ & 100,0 & $29.237,8$ & 100,0 \\
\hline
\end{tabular}

Fonte: Baccarin et al, 2015.

Ações das Prefeituras Municipais - Cumprimento do Artigo 14

Os dados aqui utilizados são provenientes da sistematização feita pelo FNDE, disponível em seu site, das prestações de contas dos gastos com alimentação escolar de prefeituras e secretarias estaduais de educação, lembrando que ainda são preliminares.

O gráfico 1 aponta para crescimento significativo do cumprimento do Artigo 14 pelo conjunto dos municípios paulistas, embora o gasto mínimo de $30 \%$ ainda não tenha sido atingido. A capital paulista demorou relativamente mais para começar a executar o Artigo 14 e, em 2014, gastou 9,0\% dos repasses do FNDE com a compra de alimentos de agricultores familiares. Já a Secretaria Estadual de Educação, na prática, não aderiu a essa ação, gastando 2,5\% em 2011, 0,0\% em 2012 e 2013 e $0,1 \%$ em 2014 com alimentos de agricultores familiares.

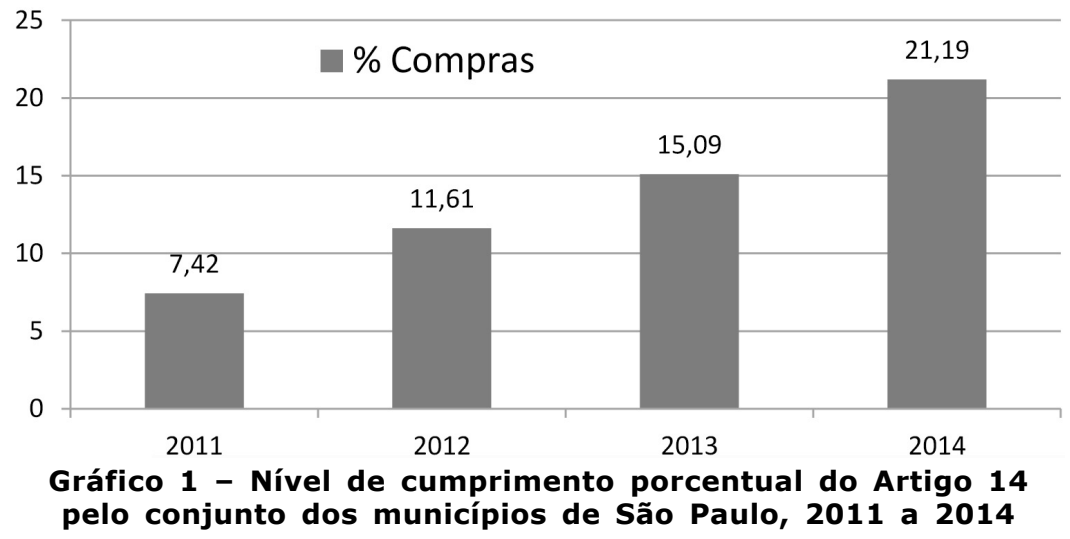

Fonte: FNDE, 2015. 
Observa-se na tabela 6 que o número de prefeituras que nada compraram via Artigo 14 apresentou forte redução entre 2011 e 2014. Eram mais da metade, tendo se reduzido a pouco mais de $25,0 \%$. Por outro lado, $46,0 \%$ das prefeituras paulistas em 2014 compraram próximo a $30,0 \%$ ou mesmo superaram esse valor.

\section{Tabela 6 - Grupos de municípios de acordo com cumprimento porcentual do Artigo 14 em 2011 e 2014, São Paulo}

\begin{tabular}{l|cc|cc}
\hline \multirow{2}{*}{$\begin{array}{c}\text { Nível de } \\
\text { cumprimento }\end{array}$} & \multicolumn{2}{c|}{2011} & \multicolumn{2}{c}{2014} \\
\cline { 2 - 5 } & Número & Porcentual & Número & Porcentual \\
\hline $0,0 \%$ & 345 & 57,0 & 175 & 27,5 \\
$0,1-10,0 \%$ & 79 & 13,1 & 55 & 8,6 \\
$10,1-25,0 \%$ & 88 & 14,5 & 114 & 17,9 \\
$25,1-35,0 \%$ & 58 & 9,6 & 114 & 17,9 \\
Mais de 35,0\% & 35 & 5,8 & 179 & 28,1 \\
\hline
\end{tabular}

Fonte: FNDE, 2015.

\section{Atratividade para Agricultores Familiares}

Baccarin et al (2011) informam que o FNDE repassou em 2010 para prefeituras e Secretaria Estadual da Educação de São Paulo um valor de R\$542,1 milhões para alimentação escolar, o que permitira a compra de $\mathrm{R} \$ 162,6$ milhões de alimentos dos agricultores familiares, caso o Artigo 14 fosse integralmente cumprido. Esse último valor equivalia à $3,2 \%$ da renda bruta da agricultura familiar do Estado, apurada pelo Censo Agropecuário de 2006 (IBGE, 2009) e corrigida pela inflação para 2010.

Especificando-se o estudo para alguns produtos, estimou-se que a produção da agricultura familiar paulista poderia atender com folgas as necessidades do consumo de frango e de mandioca, com alguma dificuldade o consumo de leite e feijão e ficaria muito distante de atender a necessidade de arroz da alimentação escolar no Estado (BACCARIN et al, 2011).

Outra conta que pode ser feita refere-se ao número de agricultores que poderiam ser contemplados. Supondo-se que não ocorresse compra de outros estados e que cada agricultor participante do PNAE recebesse $\mathrm{R} \$ 20.000,00 / a n o$, o repasse de $\mathrm{R} \$ 640,7$ milhões do FNDE e o correspondente R\$192,2 milhões para agricultores familiares, permitira que 9.610 deles fossem contemplados, equivalente a $6,4 \%$ dos 151.015 agricultores familiares paulistas registrados no Censo 2006 (IBGE, 2009).

Grande parte das prefeituras de São Paulo, ao cumprir o Artigo 14 (e gastando $\mathrm{R} \$ 20.000,00$ /agricultor), beneficiaria pequeno número de agricultores, conforme tabela 7. Pouco mais de $75 \%$ das prefeituras apenas conseguiria comprar de até 10 agricultores, tendo pequena capacidade de intervenção na renda de seus agricultores.

Apenas sete prefeituras ou $1,2 \%$ atenderiam mais de 100 agricultores. Merece destaque a situação da prefeitura de São Paulo, que poderia comprar de 1.422 agricultores familiares, bem acima daqueles existentes em sua área territorial. No caso da Secretaria Estadual da Educação, em executando plenamente o Artigo 14, conseguiria atingir 2.001 agricultores familiares.

Os grandes municípios são muito mais atrativos para os agricultores familiares. De acordo com Corá e Belik (2012), as 100 maiores prefeituras brasileiras (1,7\% do total) recebem cerca de $30 \%$ dos recursos de alimentação escolar repassados aos municípios, sendo que 36 delas estão situados no estado de São Paulo. 


\section{Tabela 7 - Municípios paulistas, classificados em faixas de acordo com número de agricultores atendíveis pela aplicação do Artigo 14, 2014}

\begin{tabular}{|c|c|c|c|c|c|}
\hline \multirow{2}{*}{$\begin{array}{c}\text { Faixa de } \\
\text { agricultores }\end{array}$} & \multicolumn{2}{|c|}{ Municípios } & \multirow{2}{*}{$\begin{array}{c}\text { Faixa de } \\
\text { agricultores }\end{array}$} & \multicolumn{2}{|c|}{ Municípios } \\
\hline & Número & Percentagem & & Número & Percentagem \\
\hline até 5 & 397 & 62,3 & 101 a 200 & 5 & 0,8 \\
\hline 6 a 10 & 94 & 14,8 & 201 a 500 & 1 & 0,2 \\
\hline 11 a 20 & 67 & 10,5 & 501 a 1000 & 0 & 0,0 \\
\hline 21 a 50 & 55 & 8,6 & mais 1.000 & 1 & 0,2 \\
\hline 51 a 100 & 17 & 2,7 & Total & 637 & 100,0 \\
\hline
\end{tabular}

Fonte: FNDE, 2015.

Para ser avaliada em futuros estudos, estabelece-se a suposição de que as grandes cooperativas de agricultores familiares vão direcionar seus esforços especialmente para venda de alimentos às grandes cidades. E estas, por questões administrativas e operacionais, vão preferir fazer contratos com essas organizações que envolvem grande número de agricultores e, portanto, grande quantidade de alimentos a ser entregue, além de maior capacidade de processamento de seus produtos.

\section{Condições Produtivas e Organização dos Agricultores}

Como já dito, supõe-se que a maior importância dos agricultores familiares em determinada região ou estado torna mais factível o cumprimento do Artigo 14. Baccarin et al (2015) apresentam números a comprovar tal fato, sendo que contra $21,2 \%$ de atendimento do Artigo 14 pelas prefeituras em São Paulo, no Paraná, com maior importância da agricultura familiar, as prefeituras gastavam $26,3 \%$ e as prefeituras de Santa Catarina, com porcentual ainda maior de agricultores familiares, superavam o mínimo do Artigo 14, gastando 38,8\% dos repasses do FNDE com alimentos oriundos de seus agricultores familiares em 2014.

Além da menor importância relativa de sua agricultura familiar, os resultados do estado de São Paulo, muito provavelmente, são influenciados pela grande expansão da área canavieira, o que se acentuou no presente Século. Excluindo as pastagens, a cana-de-açúcar ocupa área pouco superior à soma da área de todas as outras atividades agrícolas do Estado e sua produção ocorre em extensos estabelecimentos, inclusive com o arrendamento de terras de pequenos proprietários rurais (BACCARIN et al., 2015a).

Não parece ser um problema importante o nível de formalização dos agricultores familiares paulistas, pelo menos no que se refere à posse de DAP. Em 2011 foi constatado que 97.717 agricultores familiares apresentaram DAP ativa em São Paulo (MDA, 2011), número expressivo frente aos 151.015 estabelecimentos de agricultura familiar elencados no Censo de 2006.

As entrevistas realizadas nos projetos de pesquisa já citados revelaram que as compras institucionais do PNAE (e também do PAA) vêm contribuindo para a criação de associações e, em menor número, de cooperativas de agricultores familiares em São Paulo. Mas, é bom que se diga que, não raramente, foi comentado que essas instituições agem como meros intermediários na comercialização dos produtos obtidos pelos agricultores familiares, com esses não participando nerm influenciando de fato nas ações e resultados das associações. 


\section{Preços Recebidos pelos Agricultores Familiares}

Ao contrário do que impõe a regulamentação do Artigo 14, observou-se que muitas chamadas públicas não continham a informação dos preços dos produtos a serem adquiridos. Em 2012, apenas 27,4\% das chamadas públicas das prefeituras paulistas analisadas traziam essa informação, o que se elevou para 37,2\% em 2013. Isso, além de revelar a ilegalidade e má qualidade das chamadas públicas, fez com que se resumisse a análise de preços apenas àquelas prefeituras das quais se obteve os contratos de compra dos agricultores familiares.

De maneira geral, os preços praticados no Artigo 14 são maiores que os observados no PAA e os registrados em nível de produtor pelo Instituto de Economia Agrícola (IEA) da Secretaria de Agricultura e Abastecimento do Governo do Estado de São Paulo.

Foi possível fazer comparação para maior número de produtos entre preços das chamadas públicas e os no atacado, registrados pela Central de Entrepostos e Armazéns Gerais do Estado de São Paulo (CEAGESP), basicamente produtos vegetais in natura e ovo de galinha. A tabela 8 mostra que número muito reduzido de produtos, apenas $2 \%$, contou com preços abaixo de $50 \%$ daqueles praticados na CEAGESP. Supondo que os preços no atacado costumam se situar em patamar superior ao dobro dos preços recebidos pelos agricultores, os resultados apontam que os preços obtidos nos contratos do Artigo 14 são vantajosos aos agricultores familiares. Número expressivo, de $36,0 \%$, dos preços nos contratos superaram os preços da CEAGESP em mais de $50 \%$.

\section{Tabela 8 - Comparação dos preços dos contratos do Artigo 14 de prefeituras paulistas com preços no atacado da CEAGESP, São Paulo, 2012 e 2013}

\begin{tabular}{l|rr|rr|rr}
\hline \multicolumn{1}{c|}{$\begin{array}{c}\text { Faixa Preço em } \\
\text { Relação CEAGESP }\end{array}$} & \multicolumn{2}{|c|}{2012} & \multicolumn{2}{c|}{2013} & \multicolumn{2}{c}{ Total } \\
\cline { 2 - 7 } & Número & $\%$ & Número & $\%$ & Número & $\%$ \\
\hline Até $50 \%$ & 1 & 0,7 & 6 & 2,7 & 7 & 2,0 \\
De $50 \%$ a 100\% & 46 & 33,8 & 68 & 30,9 & 114 & 32,0 \\
De $100 \%$ a 150\% & 36 & 26,5 & 71 & 32,3 & 107 & 30,1 \\
Mais de 150\% & 53 & 39,0 & 75 & 34,1 & 128 & 36,0 \\
Total & 136 & 100,0 & 220 & 100,0 & 356 & 100,0 \\
\hline
\end{tabular}

Fonte: Baccarin et al, 2015.

Tal situação não indica, necessariamente, que as prefeituras estejam pagando na compra de produtos da agricultura familiar preços mais altos do que nas compras tradicionais para alimentação escolar. Muitas vezes, as prefeituras compram seus produtos a preço de varejo e não de atacado, como são os da CEAGESP.

\section{CONSIDERAÇÕES FINAIS}

Constatou-se no conjunto das prefeituras paulistas que houve crescimento expressivo da execução de compras de produtos de agricultores familiares para a alimentação escolar, entre 2011 e 2014, com aproximadamente 40\% dos municípios atingindo o mínimo de $30 \%$ previsto no Artigo 14 da Lei do PNAE. Diferentemente, a 
Secretaria Estadual da Educação, praticamente, não registrou compras de agricultores familiares no mesmo período.

Constaram-se importantes deficiências na execução do Artigo 14. Parte significativa das chamadas públicas apresenta lacunas, não informando a periodicidade e locais de entrega e os preços a serem pagos. Ao mesmo tempo, observou-se que entre os produtos requeridos predominam os de origem vegetal e in natura, o que condiz com as dificuldades dos agricultores fornecerem produtos processados, especialmente de origem animal, com maiores exigências sanitárias. Ao mesmo tempo, a priorização de produtos in natura vem ao encontro da diretriz de melhoria da qualidade nutricional da alimentação escolar, à medida que substituam produtos muito processados.

Embora, nesse ponto, a amostra fosse pequena, conseguiu-se perceber que os agricultores são mais bem remunerados ao venderem para o PNAE do que nos mercados em que tradicionalmente comercializam seus produtos. Também pode se verificar, na mesma amostra reduzida, que tem se dado prioridade nas compras a agricultores do próprio município da Entidade Executora do PNAE, seguido por agricultores de cidades próximas.

Esses dois pontos revelam que a aplicação do Artigo 14 tem se mostrado adequada ao aumento de renda de agricultores e ao desenvolvimento local, ainda que com alcance bastante limitado. A grande maioria dos municípios consegue atender pequeno número de agricultores de sua área e os recursos repassados pelo FNDE representam parcela reduzida da renda e do número de agricultores do estado de São Paulo.

Pode-se perceber que os agricultores são estimulados a aumentarem sua formalidade e organização, com o surgimento de associações e algumas cooperativas, o que representa ganho social importante. Contudo, em alguns casos, os interesses dessas entidades se apartam daqueles dos agricultores familiares e elas atuam como os intermediários dos mercados tradicionais. Constatou-se também a possibilidade dos preços convidativos incentivarem comportamentos oportunistas de agentes que forjam a condição de agricultores familiares.

Visando aumentar seu alcance social, julga-se necessário que se acrescente outras ações públicas ao Artigo 14, no campo da comercialização dos produtos dos agricultores familiares. Pode-se procurar usar para tanto outros programas já existentes como o PAA, a orientação que, a partir de 2016, órgãos públicos federais que adquiram alimentos (hospitais, universidades, forças armadas etc.) gastem no mínimo $30 \%$ dos recursos para tal fim na compra de produtos de agricultores familiares e o PPAIS (Programa Paulista da Agricultura de Interesse Social). Além disso as prefeituras podem procurar desenvolver equipamentos alternativos de comercialização, como varejões e feiras livres, para produtos de agricultores familiares.

Outra questão que se julga fundamental para o aprimoramento da execução do Artigo 14 é o reforço à integração das diversas áreas públicas envolvidas, entre elas, a de nutrição e alimentação escolar, a administrativa que organiza as compras e a de fomento agropecuário. Nesse mesmo sentido, seria recomendável um contato mais permanente com os agricultores familiares locais, envolvendo atividades de capacitação, para que se sintam convencidos a participarem como fornecedores da alimentação escolar, inclusive, garantindo que os preços mais remuneradores seja, de fato e em todas as situações, absorvidos por eles. 


\section{REFERÊNCIAS}

BACCARIN, J. G, TRICHES, R. M., TEO, C. P. A., FERREIRA, D. A. O., Silva, D. B. P. Relatório do Projeto CNPq: Agricultura Familiar sob a Vigência da Lei Federal 11.947/2009: Abrangência e Adequação das Chamadas Públicas, Impactos na Agricultura Local e Preços Recebidos pelos Agricultores Familiares, 2015. Documento em posse dos autores.

BACCARIN, J. G.; ALEIXO, S. S.; SILVA, D. B. P.; MENDONCA, G. G. Alimentação escolar e agricultura familiar: alcance e dificuldades para implantação do Artigo 14 da Lei $11.947 / 2009$ no estado de São Paulo. In: 490. CONGRESSO DA SOCIEDADE BRASILEIRA DE ECONOMIA, ADMINISTRAÇÃO E SOCIOLOGIA RURAL, 2011, Belo Horizonte. Anais ...: SOBER, 2011.

BACCARIN, J. G.; BUENO, G.; ALEIXO, S. S.; SILVA, D. B. P. Agricultura familiar e alimentação escolar sob a vigência da Lei 11.947/2009: adequação das chamadas públicas e disponibilidade de produtos no estado de São Paulo em 2011. In: 50. CONGRESSO DA SOCIEDADE BRASILEIRA DE ECONOMIA, ADMINISTRAÇÃO E SOCIOLOGIA RURAL, 2012, Vitória (ES). Anais ...: SOBER, 2012.

BOHNER, T. O. L. ; PEREIRA, A. B. A. S. ; GUEDES, A. C. ; DÖRR, A. C. Programa Nacional de Alimentação Escolar: uma abordagem das compras institucionais nas microrregiões da Quarta Colônia e Vale do Jaguari do estado do Rio Grande do Sul. Revista Monografias Ambientais - REMOA, Santa Maria, v. 14, n. 2, p. 31923202, 2014.

BRAGA, E. M. F.; AZEVEDO, H. S. Segurança alimentar e nutricional: os desafios da intersetorialidade. Revista Aval, Fortaleza, v. 2, n. 10, p. 57-71, 2012.

BRASIL. Instituto Brasileiro de Geografia e Estatística - IBGE. Censo Agropecuário 2006: Brasil, Grandes Regiões e Unidades da Federação. Segunda Apuração. Rio de Janeiro, 2012.

BRASIL. Lei 10.696 , de 2 de julho de 2003. Dispõe sobre a repactuação e o alongamento de dívidas oriundas de operações de crédito rural, e dá outras providências. Diário Oficial da República Federativa do Brasil, Poder Executivo, Brasília, DF, 03 de julho de 2003.

BRASIL. Lei 8.666, de 21 de junho de 1993. Regulamenta o art. 37, inciso XXI, da Constituição Federal, institui normas para licitações e contratos da Administração Pública e dá outras providências. Diário Oficial da República Federativa do Brasil, Poder Executivo, Brasília, DF, 06 de julho de 1994.

BRASIL. LEI no 11.947, de 16 de junho de 2009. Dispõe sobre o atendimento da alimentação escolar e do Programa Dinheiro Direto na Escola aos alunos da educação básica; altera as Leis nos 10.880, de 9 de junho de 2004, 11.273, de 6 de fevereiro de 2006, 11.507, de 20 de julho de 2007; revoga dispositivos da Medida Provisória no 2.178-36, de 24 de agosto de 2001, e a Lei no 8.913, de 12 de julho de 1994; e dá outras providências. Diário Oficial da República Federativa do Brasil, Poder Executivo, Brasília, DF, 17 de junho de 2009.

FNDE - Fundo Nacional de Desenvolvimento da Educação. Resolução/CD/FNDE No 4, de 2 de abril de 2015. , Altera a redação dos artigos 25 a 32 da Resolução/CD/FNDE no 26, de 17 de junho de 2013, no âmbito do Programa Nacional de Alimentação Escolar (PNAE). Diário Oficial da República Federativa do Brasil, Poder Executivo, Brasília, DF, 8 de abril de 2015. 
FNDE - Fundo Nacional de Desenvolvimento da Educação. Resolução/CD/FNDE No 38, de 16 de julho de 2009. Dispõe sobre o atendimento da alimentação escolar aos alunos da educação básica no Programa Nacional de Alimentação Escolar - PNAE. Diário Oficial da República Federativa do Brasil, Poder Executivo, Brasília, DF, 16 de julho de 2009.

FNDE - Fundo Nacional de Desenvolvimento da Educação. Resolução/CD/FNDE No 25, de 4 de julho de 2012. Altera a redação dos artigos 21 e 24 da Resolução No 38, de 16 de julho de 2009, no âmbito do Programa Nacional de Alimentação Escolar (PNAE). Diário Oficial da República Federativa do Brasil, Brasília, DF, 5 jul. 2012.

FNDE - Fundo Nacional de Desenvolvimento da Educação. Resolução/CD/FNDE No 32, de 10 de agosto de 2006. Estabelece as normas para a execução do Programa Nacional de Alimentação Escolar - PNAE. Diário Oficial da República Federativa do Brasil, Brasília, DF, 17 ago. 2006.

CORÁ, M.A.J.; BELIK, W. (Org.). Projeto Nutre SP: análise da inclusão da agricultura familiar na alimentação escolar no estado de São Paulo. São Paulo: Instituto Via Pública, 2012. 104 p.

COSTA, B. A. L.; AMORIM JUNIOR, P. C. G., SILVA, M. G. As Cooperativas de Agricultura Familiar e o Mercado de Compras Governamentais em Minas Gerais. Revista Economia Sociologia. Rural, Piracicaba, v.53, n.1, p. 109-126, 2015.

FNDE. Dados Agricultura Familiar. Disponível em: http://www.fnde.gov.br/ programas/alimentacao escolar/alimentacao escolar consultas/dados da agricultura familiar. Acesso em 20/09/2015.

MARQUES, A. A. et al. Reflexões de agricultores familiares sobre a dinâmica de fornecimento de seus produtos para a alimentação escolar: o caso de Araripe, Ceará. Saúde e Sociedade, São Paulo, v.23, n.4, p. 1329-1341, 2014.

MINISTÉRIO DO DESENVOLVIMENTO AGRÁRIO - MDA. Extrato da DAP. Disponível em http://smap13.mda.gov.br/ExtratoDap. Acesso em março de 2011.

MONTEIRO, C. A. et al. A new classification of foods based on the extent and purpose of their processing. Caderno Saúde Pública, Rio de Janeiro, v.26, n.11, p. 20392049, 2010.

SILVA, A. P. F.; SOUSA, A. A. Alimentos orgânicos da agricultura familiar no Programa Nacional de alimentação Escolar do Estado de Santa Catarina, Brasil. Revista de Nutrição, Campinas, v. 26, n. 6, p. 701-714, 2013.

SOUZA-ESQUERDO, V. F.; BERGAMASCO, S. M. P. P. Análise sobre o acesso aos programas de políticas públicas da agricultura familiar nos municípios do circuito das frutas (SP). Revista Economia e Sociologia Rural, Piracicaba, v.52, p. 205-222, 2014. Suplemento 1. 